\title{
ELECTROCARDIOGRAPHIC AND ECHOCARDIOGRAPHIC EVALUATION OF LEFT VENTRICULAR HYPERTROPHY IN HYPERTENSIVE PATIENTS- A HOSPITAL-BASED STUDY
}

\author{
Ashok Singh ${ }^{1}$, Bhaskar Baruah ${ }^{2}$, Chitralekha Baruah ${ }^{3}$ \\ 13rd Year Postgraduate Trainee, Department of Medicine, Gauhati Medical College and Hospital. \\ ${ }^{2}$ Associate Professor, Department of Medicine, Gauhati Medical College and Hospital. \\ 3 Professor, Department of Medicine, Gauhati Medical College and Hospital.
}

\section{ABSTRACT}

\section{BACKGROUND}

Left ventricular hypertrophy is associated with increased risk of cardiovascular morbidity and mortality, so its early detection is of major importance for initiation of treatment and its reversal by certain antihypertensive drugs like ARB and ACE inhibitors. The commonly employed technique for detection of LVH are echocardiography and electrocardiography. Although, ECG is a costeffective tool to detect LVH, but its reliability is often questioned when compared to Gold Standard Echocardiography.

The aim of the study is to determine the electrocardiographic and echocardiographic findings of LVH in hypertensive patients and to find out the sensitivity of electrocardiography in comparison to echocardiography in determining LVH in these patients.

\section{MATERIALS AND METHODS}

The study is a hospital-based observational study, conducted on 108 Hypertensive patients admitted in Medicine and Geriatrics ward and visited Outpatient Department of Medicine in Gauhati Medical College, Guwahati during the period from August 2016 to July 2017 after considering inclusion and exclusion criteria.

Inclusion Criteria- Age more than 12 years with Essential or Secondary Hypertension.

Exclusion Criteria- Myocardial ischaemia, cardiomyopathy, valvular heart disease and eccentric hypertrophy and bundle branch block, evidence of MI and arrhythmias on ECG. Clinical and laboratory findings were recorded in preformed proforma. Statistical analysis was performed using Microsoft Excel and GraphPad InStat 3.1 version software.

\section{RESULTS}

The study included a total of 108 Hypertensive patients, out of which 60 (56\%) were males and 48 (44\%) were females. 82 (75.92\%) had LVH by echocardiography and 37 (34.26\%) had LVH by electrocardiography. Sensitivity and specificity of ECG in diagnosing LVH is $40.24 \%$ and $86.66 \%$ respectively in comparison to echocardiography. Sensitivity is highest for Cornell Voltage criteria (40.24\%) and lowest for Sokolow-Lyon index criteria (34.14\%).

\section{CONCLUSION}

Our study shows that echocardiography is undoubtedly a better instrument for determination of Left Ventricular Hypertrophy. The study also reveals the fact that although ECG is a poor screening tool due to its low sensitivity, but because of its high specificity various factors determining LVH may independently effect determination of LVH.

\section{KEYWORDS}

Hypertension, Left Ventricular Hypertrophy, Electrocardiography, Echocardiography, Sensitivity.

HOW TO CITE THIS ARTICLE: Singh A, Baruah B, Baruah C. Electrocardiographic and echocardiographic evaluation of left ventricular hypertrophy in hypertensive patients- a hospital-based study. J. Evolution Med. Dent. Sci. 2018;7(10):1189-1193, DOI: $10.14260 /$ jemds/2018/272

\section{BACKGROUND}

Left ventricular Hypertrophy is a compensatory adaptive mechanism against increased afterload to reduce wall stress and maintain pump function and is commonly seen in hypertensive patients.

LVH is not only an adaptation to raised haemodynamic load in hypertension, but also independently associated with an enhanced risk for myocardial infarction, sudden cardiac death, congestive heart failure and stroke in general population as well as in patients with systemic

'Financial or Other Competing Interest': None.

Submission 16-01-2018, Peer Review 14-02-2018,

Acceptance 21-02-2018, Published 05-03-2018.

Corresponding Author:

Dr. Bhaskar Baruah,

Gauhati Medical College and Hospital,

Bhangaghar, Guwahati-781032, Assam.

E-mail: bhaskarbaruah1@yahoo.com ashok32singh@gmail.com

DOI: $10.14260 /$ jemds $/ 2018 / 272$

\section{(c) (i) $\$$}

hypertension. ${ }^{[1,2]}$ The Framingham heart study have shown the prevalence of $\mathrm{LVH}$ to be less than $3 \%$ using electrocardiography in general population. ${ }^{[3]}$ Using echocardiography, Framingham investigators have shown the prevalence of $\mathrm{LVH}$ to be $16 \%$ among men and $19 \%$ among women.[4] As, LVH is associated with increased risk of cardiovascular morbidity and mortality, so its early detection is of major importance for initiation of treatment and its reversal by certain antihypertensive drugs like ARB and ACE inhibitors. Left ventricular hypertrophy (LVH) detected either by electrocardiography or echocardiography, has long been recognised as a powerful predictor of serious cardiovascular sequelae.[1,2] Even in group of Hypertensive patients, where ECG and chest x-ray are normal 30\% - 40\% patients show echocardiographic evidence of LVH.[5]

\section{Aims and Objectives}

1. To determine the electrocardiographic and echocardiographic findings of LVH in hypertensive patients. 
2. To find out the sensitivity and specificity of electrocardiography in comparison to echocardiography in determining $\mathrm{LVH}$ in these patients.

\section{MATERIALS AND METHODS}

The study is a hospital-based, observational study conducted in 108 Hypertensive patients, admitted in Medicine and Geriatrics Ward and visited Outpatient Department of Medicine in Gauhati Medical College, Guwahati during the period from August 2016 to July 2017 after considering inclusion and exclusion criteria.

\section{Inclusion Criteria}

Age more than 12 years with Essential or Secondary Hypertension.

\section{Exclusion Criteria}

Myocardial ischaemia, valvular heart disease, cardiomyopathy and eccentric hypertrophy and bundle branch block, evidence of MI and arrhythmias on ECG.

All the patients fulfilling above criteria were subjected to a thorough history and complete examination including general examination and systemic examination with special reference to cardiovascular system. Blood pressure was taken with the help of mercury sphygmomanometer based on the latest recommendation by the seventh report of the Joint National Committee on prevention, detection, evaluation and treatment of high blood pressure.[6] Hypertension was defined according to JNC 7 criteria as systolic BP $>=140$ $\mathrm{mmHg}$ and diastolic BP $>=90 \mathrm{mmHg}$. Blood for CBC, ESR (mmAEFH), Liver function test, RBS, CXR (PA View), serum TSH and relevant laboratory investigations were done where indicated.

All the patients were subjected to ECG employing BPL CARDIART 108 T-DIGI and ECHO with colour Doppler employing Siemens Acuson CV70 present in the Department of Cardiology. ECG criteria used in this study were SokolowLyon index, Romhilt-Estes score and Cornell voltage criteria.

\begin{tabular}{|c|c|c|}
\hline Measurement & Criteria & \\
\hline $\begin{array}{c}\text { Sokolow-Lyon } \\
\text { Index }\end{array}$ & $S_{v 1}+\left(R_{v 5}\right.$ or $\left.R_{v 6}\right)>3.5 \mathrm{Mv}$ & \\
\hline \multirow[t]{9}{*}{$\begin{array}{c}\text { Romhilt-Estes } \\
\text { Point Score } \\
\text { System } \\
\end{array}$} & $\begin{array}{l}\text { Any limb lead R-wave or } \\
\text { S-wave } \geq 2.0 \mathrm{mV}\end{array}$ & 3 points \\
\hline & or $\mathrm{S}_{\mathrm{V} 1}$ or $\mathrm{S}_{\mathrm{V} 2} \geq 3.0 \mathrm{Mv}$ & 3 points \\
\hline & or $R_{v 5}$ to $R_{v 6} \geq 3.0 \mathrm{Mv}$ & 3 points \\
\hline & $\begin{array}{l}\text { ST-T wave abnormality } \\
\text { (No Digitalis Therapy) }\end{array}$ & 3 points \\
\hline & $\begin{array}{l}\text { ST-T wave abnormality } \\
\text { (Digitalis Therapy) }\end{array}$ & 1 point \\
\hline & Left atrial abnormality & 3 points \\
\hline & $\begin{array}{c}\text { Left axis deviation ( } \geq 30 \\
\text { degrees) }\end{array}$ & 2 points \\
\hline & QRS duration $\geq 90 \mathrm{msec}$ & 1 point \\
\hline & $\begin{array}{c}\text { Intrinsicoid deflection in } \\
V_{5} \text { or } V_{5} \geq 50 \mathrm{msec}\end{array}$ & 1 point \\
\hline \multirow[t]{2}{*}{$\begin{array}{c}\text { Cornell Voltage } \\
\text { Criteria }\end{array}$} & $\begin{array}{c}\mathrm{S}_{\mathrm{V} 3}+\mathrm{S}_{\mathrm{aVl}} \geq 2.8 \mathrm{mV} \text { (for } \\
\text { men) }\end{array}$ & \\
\hline & $\begin{array}{c}\mathrm{S}_{\mathrm{V} 3}+\mathrm{S}_{\mathrm{aVl}} \geq 2.0 \mathrm{mV} \text { (for } \\
\text { women) }\end{array}$ & \\
\hline
\end{tabular}

For Romhilt-Estes point score, a score of more than equal to 5 was suggestive of $\mathrm{LVH}$. The left ventricular mass index (LVMI) was calculated using Dubois Formula and expressed in gram/square meter. In females, LVMI of $>=96 \mathrm{~g} / \mathrm{m}^{2}$ and in males LVMI of $>=116 \mathrm{~g} / \mathrm{m}^{2}$ was taken as LVH.

Left ventricular mass determined by echocardiography was chosen as the Gold standard for determining LVH to be used for the comparison with electrocardiographic data, because various previous reports showed a good correlation between this method and necropsy data.7-10

In our study, Body mass index (BMI) $>=25 \mathrm{~kg} / \mathrm{m}^{2}$ is considered as obese individual and smoking was defined in case a subject was smoking 5 or more bidis, cigarette, hukka for 5 years or more.[11]

\section{Statistical Analysis}

Data obtained from these patients were systematically recorded and analysed using Microsoft Excel and GraphPad InStat 3.1 version. Fisher exact test was used to analyse statistical significance. $\mathrm{P}$ value of $<0.05$ was considered significant. The test was run after finding sensitivity and specificity of ECG with Gold standard echocardiography.

\section{RESULTS}

This study included a total of 108 hypertensive patients. Out of 108 patients, $60(56 \%)$ were males and $48(44 \%)$ were females [Table 1]. In this study 47 patients (41\%, 24 males and 20 females) were smokers and 44 patients $(44 \%, 35$ males and 12 females) were obese. The age of the patients varied from 23 to 90 yrs. with most of the patients falling in the age group of 51 - 70 yrs., 49 patients i.e. $45.37 \%$ [Figure2].

The mean age of the patients in our study population was 56.36 yrs. The mean age of males were 59.56 yrs. and mean age of females were 53.17 yrs. The mean BMI was 25.09 $\mathrm{kg} / \mathrm{sqm}$, which were more in females $25.64 \mathrm{~kg} / \mathrm{sqm}$ than males $24.55 \mathrm{~kg} / \mathrm{sqm}$. The mean LVMI was $130.80 \mathrm{~g} / \mathrm{sqm}$, which were more for males than females $123.56 \mathrm{~g} / \mathrm{sqm}$. The mean systolic BP was $158.813 \mathrm{mmHg}$ and diastolic BP was $98.404 \mathrm{mmHg}$. LVH has been diagnosed in 82 (75.92\%) patients by Echocardiography and 37 (34.26\%) patients by electrocardiogram [Table 1]. The ECG and Echo findings of $\mathrm{LVH}$ with respect to gender and presence/ absence of risk factors (obesity and smoking) has been shown in Table 2, 3, $4,5,6$, 7. Echocardiographically detected LVH has been found to be more in females than males $(p=0.5069)$, smokers than non-smokers $(\mathrm{p}=.0059)$ and obese than non-obese patients $(p=0.6475)$. Using electrocardiogram LVH has been diagnosed more in males than females $(p=.6837)$, nonsmokers than smokers $(p=.1058)$ and non-obese than obese patients $(\mathrm{p}=.1034)$. The sensitivity of different ECG criteria in comparison to echocardiography has been mentioned in Table 8 . The sensitivity of different ECG criteria with respect to gender and presence/ absence of risk factors (smoking and obesity) has been depicted in Table 9 . 


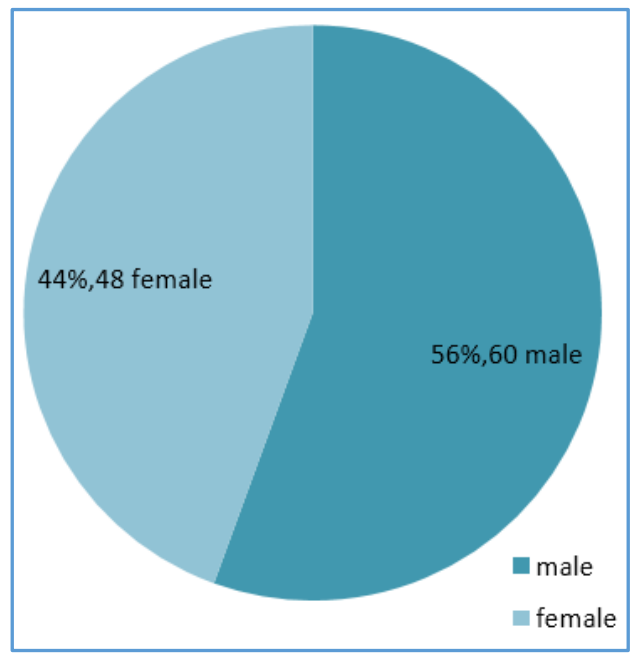

Figure 1. Pie Diagram showing Sex Distribution of the Patients

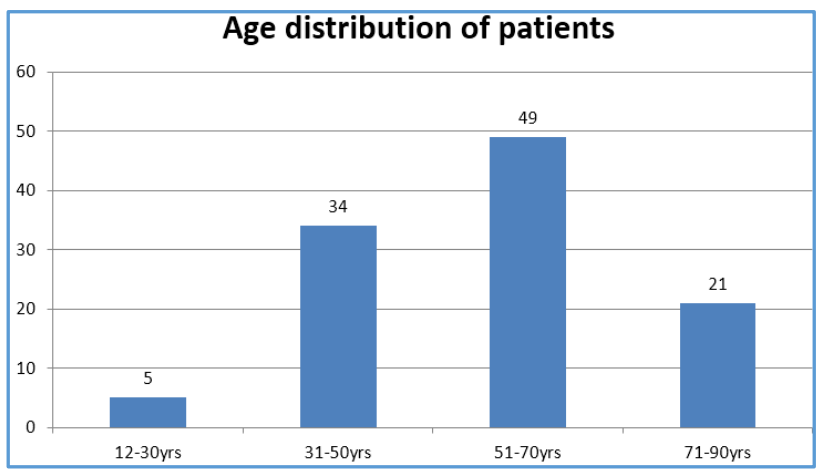

Figure 2. Bar Diagram showing Age Distribution of Patients

\begin{tabular}{|c|c|c|}
\hline Parameters & Patients with LVH & Percentage \\
\hline Echocardiography (LVMI) & 82 & $75.92 \%$ \\
\hline $\begin{array}{c}\text { Overall ECG (any below } \\
\text { criteria) }\end{array}$ & 37 & $34.26 \%$ \\
\hline Sokolow-Lyon & 31 & $28.70 \%$ \\
\hline Romhilt-Estes & 34 & $31.48 \%$ \\
\hline Cornell Voltage & 36 & $33.33 \%$ \\
\hline
\end{tabular}

Table 1. Showing LVH in Patients according to Different ECG Criteria used and Echocardiography

\begin{tabular}{|c|c|c|}
\hline Parameters & LVH in Male Patients & Percentage \\
\hline Echo (LVMI) & 44 & $73.33 \%$ \\
\hline $\begin{array}{c}\text { Overall ECG (any } \\
\text { below criteria) }\end{array}$ & 22 & $36.66 \%$ \\
\hline Sokolow-Lyon & 18 & $30 \%$ \\
\hline Romhilt-Estes & 19 & $31.66 \%$ \\
\hline Cornell Voltage & 21 & $35 \%$ \\
\hline \multicolumn{2}{|c|}{ Table 2. Showing LVH in Male Patients according to } \\
different ECG Criteria used and Echocardiography \\
\hline
\end{tabular}

\begin{tabular}{|c|c|c|}
\hline Parameters & LVH in Female Patients & Percentage \\
\hline Echo (LVMI) & 38 & $79.16 \%$ \\
\hline $\begin{array}{c}\text { Overall ECG (any } \\
\text { below criteria) }\end{array}$ & 15 & $31.25 \%$ \\
\hline Sokolow-Lyon & 13 & $27.08 \%$ \\
\hline Romhilt-Estes & 15 & $31.25 \%$ \\
\hline Cornell Voltage & 15 & $31.25 \%$ \\
\hline \multicolumn{2}{|c|}{ Table 3. Showing LVH in Female Patients by } \\
Electrocardiography and Echocardiography \\
\hline
\end{tabular}

\begin{tabular}{|c|c|c|}
\hline Parameters & LVH in Obese Patients & \% \\
\hline Echo (LVMI) & 38 & $86.36 \%$ \\
\hline $\begin{array}{c}\text { Overall ECG (Any } \\
\text { below criteria) }\end{array}$ & 11 & $25 \%$ \\
\hline Sokolow-Lyon & 10 & $22.72 \%$ \\
\hline Romhilt-Estes & 10 & $22.72 \%$ \\
\hline Cornell Voltage & 11 & $25 \%$ \\
\hline Table 4. Showing LVH in ECG by different Criteria and \\
Echocardiography in BMI >= 25 (Obese Patients) \\
\hline
\end{tabular}

\begin{tabular}{|c|c|c|}
\hline Parameters & LVH in Non-Obese Patients & $\mathbf{\%}$ \\
\hline Echo (LVMI) & 44 & $68.75 \%$ \\
\hline $\begin{array}{c}\text { Overall ECG (Any } \\
\text { below criteria) }\end{array}$ & 26 & $40.62 \%$ \\
\hline Sokolow-Lyon & 21 & $32.81 \%$ \\
\hline Romhilt-Estes & 24 & $37.5 \%$ \\
\hline Cornell Voltage & 25 & $39.06 \%$ \\
\hline
\end{tabular}

Table 5. Showing LVH in Non-Obese Patients (BMI < 25) by different ECG Criteria and Echocardiography

\begin{tabular}{|c|c|c|}
\hline Parameters & LVH in Smoker Patients & Percentage \\
\hline Echo (LVMI) & 42 & $89.36 \%$ \\
\hline $\begin{array}{c}\text { Overall ECG (Any } \\
\text { Below Criteria) }\end{array}$ & 12 & $25.53 \%$ \\
\hline Sokolow-Lyon & 10 & $21.27 \%$ \\
\hline Romhilt-Estes & 11 & $23.40 \%$ \\
\hline Cornell Voltage & 12 & $25.53 \%$ \\
\hline Table 6. Showing LVH in Smoker by different ECG Criteria \\
and Echocardiography \\
\hline
\end{tabular}

\begin{tabular}{|c|c|c|}
\hline Parameters & LVH in Non-Smoker Patients & $\mathbf{\%}$ \\
\hline Echo (LVMI) & 40 & $65.57 \%$ \\
\hline $\begin{array}{c}\text { Overall ECG (Any } \\
\text { Below Criteria) }\end{array}$ & 25 & $41 \%$ \\
\hline Sokolow-Lyon & 22 & $36.06 \%$ \\
\hline Romhilt-Estes & 23 & $37.70 \%$ \\
\hline Cornell Voltage & 24 & $39.34 \%$ \\
\hline
\end{tabular}

Table 7. Showing LVH in Non-Smoker by different ECG Criteria and Echocardiography

\begin{tabular}{|c|c|c|}
\hline ECG Criteria & Sensitivity & Specificity \\
\hline Romhilt-Estes & $36.58 \%$ & $86.66 \%$ \\
\hline Cornell Voltage & $40.24 \%$ & $89.65 \%$ \\
\hline Sokolow-Lyon & $34.14 \%$ & $89.65 \%$ \\
\hline $\begin{array}{c}\text { Overall ECG (Any } \\
\text { above Criteria) }\end{array}$ & $40.24 \%$ & $86.66 \%$ \\
\hline
\end{tabular}

Table 8. Showing Sensitivity and Specificity of different ECG Criteria in Comparison to Echocardiography

\begin{tabular}{|c|c|c|c|}
\hline Factors & $\begin{array}{c}\text { Romhilt- } \\
\text { Estes Score }\end{array}$ & $\begin{array}{c}\text { Cornell } \\
\text { Voltage }\end{array}$ & $\begin{array}{c}\text { Sokolow- } \\
\text { Lyon Index }\end{array}$ \\
\hline Male & $38.63 \%$ & $45.45 \%$ & $36.36 \%$ \\
\hline Female & $34.21 \%$ & $34.21 \%$ & $31.57 \%$ \\
\hline Obese & $31.25 \%$ & $34.37 \%$ & $31.25 \%$ \\
\hline Non-Obese & $40 \%$ & $44 \%$ & $40 \%$ \\
\hline Smoker & $27.5 \%$ & $30 \%$ & $25 \%$ \\
\hline Non-Smoker & $45.23 \%$ & $50 \%$ & $45.23 \%$ \\
\hline Table 9. Showing Sensitivity of different ECG Criteria \\
according to different Factors like Sex, Obesity and \\
Smoking \\
\hline
\end{tabular}

\section{DISCUSSION}

In this study $82(75.92 \%)$ patients have been found to have LVH by echocardiography, which is similar to study by Dubey 
et al.[12] Dubey et al[12] in their study on 151 patients found LVH in 113 patients by echocardiography (74.8\%).

In our study electrocardiography could diagnose LVH in 37 (34.26\%) patients, which is similar to study done by Abid et al.[13] Abid et al ${ }^{13}$ in similar study on 50 patients found left ventricular hypertrophy in 22 (44\%) on electrocardiography.

In this study sensitivity and specificity of electrocardiography in diagnosing LVH has been $40.24 \%$ and $86.66 \%$ respectively, which is similar to study by Devereux et al. ${ }^{15}$ Devereux et al $^{14}$ found a sensitivity of $34 \%$ and a specificity of $98 \%$ in the comparison with left ventricular mass shown by the echocardiogram without differences between results for either sex.

In this study, sensitivity and specificity of Sokolow-Lyon voltage criteria has been $34.14 \%$ and $89.65 \%$ respectively, which is similar to study by Casale et al (Sensitivity-33\%, Specificity-94\%) and Norman et al[15] (Sensitivity-30\%, Specificity-86\%).

In our study sensitivity and specificity using RomhiltEstes scoring criteria has been $36.58 \%$ and $86.66 \%$ respectively, which is similar to studies conducted by Waqas Hameed et al ${ }^{16}$ (Sensitivity-31\%, Specificity-86\%) and Casale et al ${ }^{17}$ (Sensitivity-33\%, Specificity-94\%).

In our study sensitivity and specificity using Cornell Voltage Criteria has been $40.24 \%$ and $89.65 \%$ respectively, which is similar to study conducted by Casale et al ${ }^{17}$ (Sensitivity-42\%, Specificity-96\%).

In our study, 38 (79.16\%) female patients and 44 $(73.33 \%)$ male patients have been found to have LVH by echocardiography. Echocardiography could diagnose LVH more in females than males, which was statistically not significant $(p=.5069)$ and is similar with study done by Dubey et al.[12]

In this study electrocardiography could diagnose LVH in 22 patients $(36.66 \%)$, which is higher in males than females 15 patients $(31.25 \%)$ that is statistically not significant $(\mathrm{p}=0.6837)$, which is similar to study by Okin et al. ${ }^{18}$

Okin et $\mathrm{al}^{18}$ in a study on 389 patients found LVH in 116 patients suggesting that the worse performance of the ECG in women might be partially attributed to the lower voltage and duration of QRS complexes due to the differences in body surface and heart dimensions observed between the genders.

In our study in male, sensitivity of Sokolow-Lyon, Romhilt-Estes and Cornell voltage criteria has been $36.36 \%$, $38.63 \%$ and $45.45 \%$ respectively. Sensitivity has been highest for Cornell voltage in male, which is similar to study by Alfakih et al.[19]

In our study in female sensitivity of Sokolow-Lyon, Romhilt-Estes and Cornell voltage criteria has been $31.57 \%$, $34.21 \%$ and $34.21 \%$ respectively, which is similar to study by Venugopal et al,[20] but only varies in sensitivity which may be attributed to difference in BMI and race.

In this study echocardiography diagnosed LVH in 38 obese patients $(86.36 \%)$, which is higher than non-obese 44 patients $(68.75 \%)$, that is statistically not significant ( $p=0.6475)$ and is similar to study by Dubey et al.[12]

In this study electrocardiography could diagnose LVH in $26(40.62 \%)$ non-obese patients, which is higher than obese patients $11(25 \%)$ and is statistically not significant $(\mathrm{p}=0.1034)$. Obesity attenuates precordial voltage and reduce the sensitivity of electrocardiography.
In obese patients, sensitivity of Sokolow-Lyon, RomhiltEstes and Cornell voltage criteria was $31.25 \%, 31.25 \%$ and $34.37 \%$ respectively. In non-obese patients, sensitivity of Sokolow-Lyon, Romhilt-Estes and Cornell voltage criteria was $40 \%, 40 \%$ and $44 \%$ respectively and which was similar to study done by Rodrigues et al.[21]

In this study, echocardiography diagnosed LVH in 42 smoker patients $(89.36 \%)$ which is higher than non-smoker patients $40(65.57 \%)$ patients, that is statistically significant $(p=0.0059)$ which is similar to study done by Venugopal et al.[20]

In our study electrocardiography could diagnose LVH in 25 (41\%) non-smoker patients, which is higher than smoker patients $12(25.53 \%)$ that is statistically not significant ( $p=0.1058$ ) which is similar to study by Schillaci $G$ et al.[22]

In this study in non-smoker patients, sensitivity of Sokolow-Lyon, Romhilt-Estes and Cornell voltage criteria has been $45.23 \%, 45.23 \%$ and $50 \%$ respectively. In smoker patients, sensitivity of Sokolow-Lyon, Romhilt-Estes and Cornell voltage criteria has been $25 \%, 27.5 \%$ and $30 \%$. Our study in relation to risk factor, smoking is similar to study done by Schillaci G et al.[22]

Schillaci G[22] et al also showed that Electrocardiography (ECG) has a lower sensitivity for the diagnosis of left ventricular (LV) hypertrophy in smokers than in nonsmokers.

\section{CONCLUSION}

This study included a total of 108 hypertensive patients, where 82 (75.92\%) patients showed LVH by echocardiography and 37 patients (34.26\%) by echocardiography. Sensitivity and specificity of ECG in diagnosing LVH was $40.24 \%$ and $86.66 \%$ respectively in comparison to echocardiography. Sensitivity has been highest for Cornell Voltage criteria (40.24\%) and lowest for SokolowLyon voltage criteria (34.14\%).

This study shows that obesity, smoking and female gender decreases the sensitivity of electrocardiography and increases the sensitivity of echocardiography.

The study shows that echocardiography is undoubtedly a better instrument for determination of Left Ventricular Hypertrophy. The study also reveals that although ECG is a poor screening tool due to its low sensitivity, but because of its high specificity various factors determining LVH may independently effect determination of LVH.

\section{REFERENCES}

[1] Kannel WB, Gordon T, Offutt D. Left ventricular hypertrophy by electrocardiogram. Prevalance, Incidence and mortality in the Framingham Study. Ann Intern Med 1969;71(1):89-105.

[2] Levy D, Garrison RJ, Savage DD, et al. Prognostic implications of echocardiography determined left ventricular mass in Framingham Heart Study. N Engl J Med 1990;322(22):1561-6.

[3] Savage DD, Garrison RJ, Kannel WB, et al. The spectrum of left ventricular hypertrophy in a general population sample: the Framingham study. Circulation 1987;75(1 Pt 2):I26-I33.

[4] Savage DD. Overall risk of left ventricular hypertrophy secondary to systemic hypertension. Am J Cardiol 1987;60(17):8I-12I. 
[5] Casale PN, Devereux RB, Klingfield P, et al. Electrocardiographic detection of left ventricular hypertrophy: development and prospective validation of improved criteria. J Am Coll Cardiol 1985;6(3):57280.

[6] Chobanian AV, Bakris GL, Black HR, et al. The seventh report of the Joint National Committee on Prevention, detection, evaluation and Treatment of high blood pressure: the JNC 7 report. Jama 2003;289(19):256072.

[7] Devereux RB. Detection of left ventricular hypertrophy by M-mode echocardiography. Anatomic validation, standardization and comparison to other methods. Hypertension 1987;9(2 Pt 2):II19-II26.

[8] Devereux RB, Reichek N. Echocardiographic determination of left ventricular mass in man. Anatomic validation of the method. Circulation 1977;55(4):613-8.

[9] Reichek N, Helak J, Plappert T, et al. Anatomic validation of left ventricular mass estimates from clinical two-dimensional echocardiography: initial results. Circulation 1983;67(2):348-52.

[10] Devereux RB, Alonso DR, Lutas EM, et al. Echocardiographic assessment of left ventricular hypertrophy: comparison to necropsy findings. Am J Cardiol 1986;57(6):450-8.

[11] Maheswari VD, Pillai A. Influence of smoking and hypertension on left ventricular mass. JAPI 2000;48(4):397-9.

[12] Dubey TN, Paithankar U, Yadav BS. Correlation of echocardiographic left ventricular mass index and electrographic left ventricular hypertrophy variables. International Journal of Contemporary Medical Research 2016;3(5):1287-9.

[13] Khan AA, Alam Z, Inayat S. Electrocardiographic correlation of left ventricular hypertrophy (in cases of Hypertension) with echocardiography. Pakistan Heart Journal 2003;36(1-4):17-9.

[14] Devereux RB, Casale PN, Eisenberg RR, et al. Electrocardiographic detection of left ventricular hypertrophy using echocardiographic determination of left ventricular mass as the reference standard. Comparison of standard criteria, computer diagnosis and physician interpretation. J Am Coll Cardiol 1984;3(1):82-7.
[15] Norman JE, Levy D. Improved electrocardiographic detection of echocardiographic left ventricular hypertrophy: results of a correlated data base approach. J Am Coll Cardiol 1995;26(4):1022-9.

[16] Hameed W, Razi MS, Khan MA, et al. Echocardiographic diagnosis of left ventricular hypertrophy: comparison with echocardiography. Pak J Physiol 2005;1(1-2):35-8.

[17] Casale PN, Devereux RB, Alonso DR, et al. Improved sex - specific criteria of left ventricular hypertrophy for clinical and computer interpretation of electrocardiograms: validation with autopsy findings. Circulation 1987;75(3):565-72.

[18] Okin PM, Roman MJ, Devereux RB, et al. Gender differences and the electrocardiogram in left ventricular hypertrophy. Hypertension 1995;25(5):242-9.

[19] Alfakih K, Walters K, Jones T, et al. New genderspecific partition values for ECG criteria of left ventricular hypertrophy: recalibration against cardiac MRI. Hypertension 2004;44(2):175-9.

[20] Venugopal K, Gadwalkar SR, Ramamurthy P. Electrocardiogram and echocardiographic study of left ventricular hypertrophy in patients with essential hypertension in a teaching medical college. J Sci Soc 2016;43(2):75-9.

[21] Rodrigues JCL, McIntyre B, Dastidar AG, et al. The effect of obesity on electrocardiographic detection of hypertensive left ventricular hypertrophy: recalibration against cardiac magnetic resonance. The Journal of Human Hypertension 2016;30(3):197-203.

[22] Schillaci G, Verdecchia P, Sacchi N, et al. Influence of cigarette smoking on the electrocardiographic diagnosis of left ventricular hypertrophy in arterial hypertension. G Ital Cardiol 1999;29(1):34-8. 